\title{
Habituation and dishabituation of the heart rate component of the orienting response in brain-damaged patients*
}

\author{
OSCAR A. PARSONS $\dagger$, JOHN C. MESSINGER, and FRANK A. HOLLOWAY \\ University of Oklahoma Health Sciences Center \\ 800 N.E. 13, P.O. Box 26901, Oklahoma City, Oklahoma 73190
}

\begin{abstract}
Measures of the heart rate (HR) orienting response (OR), its habituation, and its dishabituation were tested in brain-damaged (BD) and nonbrain-damaged (NBD) middle-aged males. The habituation stimulus was an 80-dB pure tone, the dishabituation stimulus was a change in frequency, and a return to the original stimulus provided a test for dishabituation. A "blank" trial was scored $20 \mathrm{sec}$ after the task to provide a special dishabituation stimulus. Another "blank" trial $20 \mathrm{sec}$ before the task provided a measure of natural HR variability during rest. Both the NBD and BD exhibited ORs on Trials 1 and 2 and habituation on later trials. Change in stimulus resulted in dishabituation in the NBD but not in the BD. It is concluded that the response "model" for the OR is less elaborated and more diffuse in the BD than in the NBD $S$.
\end{abstract}

Russian experimenters (Briullova, 1965; Gamburg, 1965; Stepanov, 1965) have reported abnormalities in the orienting response (OR) and its habituation and dishabituation in patients with brain damage (BD). However, lack of experimental details in their reports precludes a systematic evaluation of the significance of these observations. Agreeing in part with the Russian literature, Holloway and Parsons (1971), using a repetitive auditory stimulus, found that the BD patients manifested habituation of the skin conductance response and alpha blocking response similar to nonbrain-damaged (NBD) control Ss, but that the BD patients: (1) did not appear to habituate the deceleration component of the heart rate (HR) response, and (2) did not manifest dishabituation on any of the above response measures.

Commenting on these findings, Stern and Janes (in press) suggest that BD may develop a less complex, or a "simpler," cortical model (Sokolov, 1963) of the stimulus over the same experimental period than do NBD Ss. Both models lead to habituation, but the simpler model of the BD is revealed by lack of response to the dishabituation stimulus.

The Stern and Janes hypothesis deserves further test, since in the Holloway and Parsons study the dishabituation stimulus was a change in auditory stimulus (buzzer) duration (from 2 to $10 \mathrm{sec}$, or vice versa). With duration being variable and half of the Ss receiving a stimulus of $10 \mathrm{sec}$ on the habituation trials, offset of the 10-sec stimulus could have produced response effects which interfered with expected

*This research was supported, in part, by NINDS Grant NB 05797. Thanks are due to the staff and patients of the Oklahoma City VA Hospital for their help in conducting this experiment and to Gary I. Parsons for scoring of the records.

† Address reprint requests to Oscar A. Parsons. habituation patterns. The present study follows the habituation paradigm but uses a brief $(.5 \mathrm{sec})$ presentation of a pure tone and change in frequency of tone as a dishabituation stimulus and a return to the original frequency as a test of dishabituation (Thompson \& Spencer, 1966). Under these experimental conditions, following the Stern and Janes model, it is expected that the HR component of the orienting response in $\mathrm{BD}$ will (1) habituate similarly to NBD, but (2) will either not dishabituate or manifest less dishabituation than NBD.

\section{METHOD}

Subjects

The total sample comprised $15 \mathrm{NBD}$ and $14 \mathrm{BD}$ male Caucasian patients at the Oklahoma City Veterans Administration Hospital. Due to either equipment failure or the presence of pronounced sinus arrythmia during the task, $6 \mathrm{NBD}$ and $3 \mathrm{BD}$ Ss were eliminated from the study. Criteria for $\mathrm{S}$ selection were the same as those reported by Holloway and Parsons (1971). The BD group comprised 4 Ss with right hemisphere damage, 4 with left, and 3 with diffuse or bilateral. In each of the subgroups, there were patients with varying degrees of frontal, temporal, and/or parietal lobe damage that had resulted from trauma, tumors, or cerebral vascular accidents. All Ss were capable of attending to and following instructions in the experiment. The two groups were not significantly different on age (overall mean $=38.45$ ) or education (overall mean $=$ 11.85).

\section{Apparatus}

Heart rate and respiration were recorded on an eight-channel Beckman Type $\mathbf{R}$ dynograph. For recording heart rate, a Beckman Type 9857 cardiotach coupler was used. Standard Grass E5S electrodes were placed on the back of the neck and over the heart. Respiration was measured with a strain gauge device fitted around the S's torso and at the level of the diaphragm. Presentation of the stimuli was accomplished by a Lehigh fixed tone generator. 

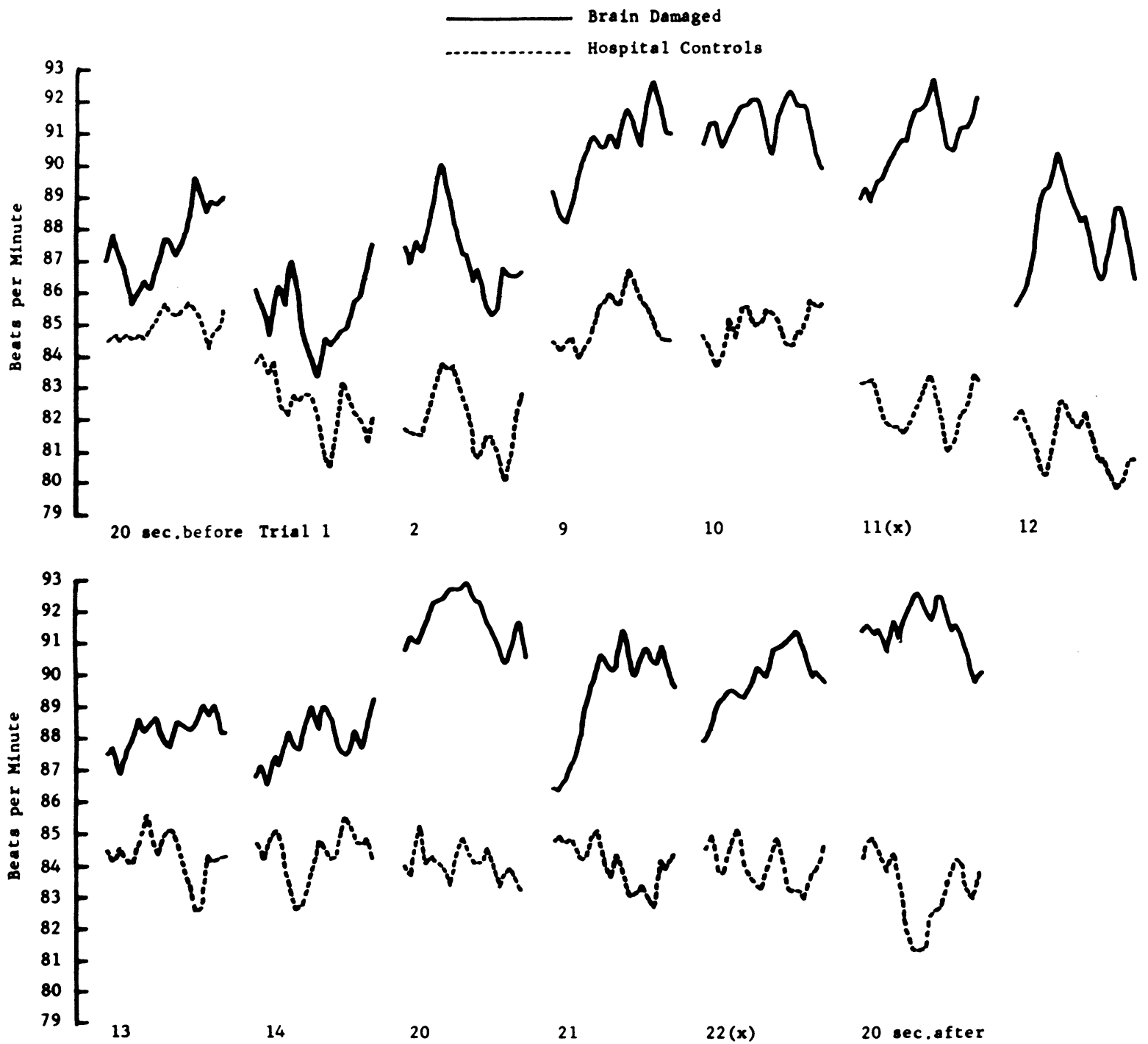

21

$22(x)$

20 sec.after

Fig. 1. Phasic HR response curves (average 20-beat curves). $X=$ dishabituation.

\section{Experimental Conditions}

The Ss were placed in a comfortable arm chair in an air-conditioned sound-attenuated room. After electrodes were attached, all lights were turned out except for a low-intensity light behind the S. A low-level "white noise" was present throughout the entire session. All recording equipment was located in an adjacent room. The tones were presented through a speaker placed in front of the $S$.

Ss received a habituation series of 22 trials, using a $2.8-\mathrm{kHz}$ tone at an intensity level of $80 \mathrm{~dB}$, with the exception of Trials 11 and 22 , which were dishabituation stimulus trials using a $4.5-\mathrm{kHz}$ tone at $80 \mathrm{~dB}$. All tones were presented at a constant 20 -sec interval and with a stimulus duration of $0.5 \mathrm{sec}$.

\section{Data Treatment}

The heart rate and respiration were scored at 13 selected points, providing specific measures: $20 \mathrm{sec}$ before the task (a basal or rest measure); Trials 1 and 2 (initial OR); Trials 9 and 10 (habituation); Trial 11 (dishabituation stimulus); Trials 12, 13, 14 (dishabituation effect); Trials 20 and 21 (habituation); Trial 22 (dishabituation stimulus); and $20 \mathrm{sec}$ after the task (a blank trial).

Heart rate on these trials was scored by a beat-by-beat analysis. For each trial within the habituation-dishabituation series, 20 beats were scored and plotted, with the first being point of stimulus onset. The measures sampled at $20 \mathrm{sec}$ before the task and $20 \mathrm{sec}$ after the task were also scored in this same manner. For respiration pre- and postmeasures of amplitude and period were taken at the point of stimulus onset. None of the results reported below can be attributed to respiration levels or changes. The extent of initial HR acceleration (highest heart beat within Beats 2-10 minus the point of stimulus onset) and HR deceleration (point of stimulus onset minus the lowest beat from 7 to 15 beats) were calculated. The presence or absence of significant HR acceleration or deceleration for each group was determined by correlated ts between point of stimulus onset and the acceleration or deceleration measure on the appropriate trial and group. Correlations between the groups' 20-beat patterns for each trial provided a measure of similarity of response. 
Table 1

Within-Group Comparisons (Correlated ts) and Between-Group Correlations (rs)

\begin{tabular}{|c|c|c|c|c|c|c|}
\hline \multirow{2}{*}{\multicolumn{2}{|c|}{ Trials }} & \multicolumn{2}{|c|}{ NBD } & \multicolumn{2}{|c|}{$\mathrm{BD}$} & \multirow[b]{2}{*}{ Correlation } \\
\hline & & Deceleration & Acceleration & Deceleration & Acceleration & \\
\hline \multicolumn{2}{|c|}{$20 \mathrm{Sec}$ Before } & -0.46 & 1.65 & $1.94 *$ & $2.69 * *$ & .40 \\
\hline $\begin{array}{l}\text { Trial No. } \\
1\end{array}$ & $\begin{array}{r}1 \\
2 \\
9 \\
10 \\
11 \\
12 \\
13 \\
14 \\
20 \\
21 \\
22\end{array}$ & $\begin{array}{c}-2.17^{*} \\
-2.01^{*} \\
-0.29 \\
-1.70 \\
-4.25 \dagger \\
2.19^{*} \\
1.73 \\
3.74 \dagger \\
-2.26^{*} \\
-3.97 \dagger \\
-3.97 \dagger\end{array}$ & $\begin{array}{l}2.41^{* *} \\
5.03 \dagger \\
2.41^{* *} \\
4.00 \dagger \\
0.98 \\
3.02^{* *} \\
2.46^{* *} \\
1.45 \\
3.11^{* *} \\
2.36^{* *} \\
1.66\end{array}$ & $\begin{array}{c}2.92 * * \\
2.34 * * \\
-1.02 \\
-0.51 \\
-0.34 \\
0.19 \\
1.83 * \\
1.13 \\
-1.04 \\
0.77 \\
-0.50\end{array}$ & $\begin{array}{l}2.51 * * \\
3.70 * * \\
4.40 \div \\
2.42 * * \\
3.05 * * \\
3.62 \div \\
2.11 * \\
3.43 \div \\
2.29 * * \\
2.86 * * \\
1.40\end{array}$ & $\begin{array}{c}.07 \\
.72 \dagger \\
.42 \\
-.27 \\
.09 \\
.05 \\
-.33 \\
-.27 \\
.35 \\
-.54 * * \\
-.51^{* *}\end{array}$ \\
\hline \multicolumn{2}{|l|}{$20 \mathrm{Sec}$ After } & $-2.88 * *$ & $2.07 *$ & -0.92 & $2.13^{*}$ & $-.48 * *$ \\
\hline
\end{tabular}

\section{RESULTS}

The curves for 20 beats following the stimulus presentation on selected trials are presented in Fig. 1. The within-group tests of significance of change and between-group pattern correlations are found in Table 1. Both the NBD and BD exhibit significant deceleration on Trials 1 and 2 . The NBD decelerate again significantly at Trial 11 and on most scored trials thereafter. Of these trials, three were measures of dishabituation stimulus effects (Trials 11 and 22 and $20 \mathrm{sec}$ after the task) while three specifically measured dishabituation (Trials 12, 13, and 14). With the exception of a trend on Trial 13, which is not different from the variability shown on the prestimulus trials, the BD showed no significant deceleration after Trial 2. On the acceleration measure, both groups had significant responses over most of the trials and thus were not discriminated.

Correlations of 20-beat patterns between the two groups at each trial were calculated both by the Eta and Pearson $r$ methods. Tests for linearity revealed that only one trial (No. 20) deviated significantly, therefore Pearson rs were appropriate. A significant positive correlation was found between the curves for the NBD and BD at Trial $2(p<.01)$, while significant negative correlations were found on the last three trials $(p<.05)$.

\section{DISCUSSION}

The beat-by-beat patterns and the correlated ts for the NBD give rise to data in accord with other studies. The response to novel stimuli is primarily a HR deceleration, and this habituates rapidly, only to be seen again when the stimuli change in Trials 11 and 22 and the blank trial and when dishabituation occurs (Trials 12, 13, and 14) (Holloway \& Parsons, 1971; Keefe, 1970; Lacy, 1967; Obrist, Wood, \& Perez-Keyes, 1965; Sokolov, 1963). The results with the BD suggest, unlike our previous findings (Holloway \& Parsons, 1971), that the BD's initial HR-OR habituates but that, similar to the previous findings, dishabituation does not occur. Cardiac deceleration in response to the stimulus is seen on Trials 1 and 2, but disappears by Trials 9 and 10 . On all trials thereafter, the BD failed to show the HR-OR.

HR acceleration proved to be a nondiscriminating measure in the present study. It was present to a significant degree in both the BD and NBD on all types of trials, i.e., habituation and dishabituation. This further supports the contention that deceleration is the measure most indicative of orientation and dishabituation (Graham \& Clifton, 1966).

The blank trial $20 \mathrm{sec}$ after the task provided a special case of a dishabituation stimulus. It appears that a temporal expectancy developed in the control group in the fixed interstimulus interval task to the expected stimulus. The BD group failed to show such an expectancy for the stimulus. According to Stern and Janes, this would be a case of an incomplete or deficient model in the BD, i.e., where temporal aspects of the stimulus are not incorporated into the model. Thus, the BD established a model which failed to acquire experimentally defined temporal and frequency aspects of the stimulus as significant characteristics of that stimulus.

An unexpected finding was that the response patterns shifted from a positive correlation in the early trials to a significantly negative correlation in the late trials. Inspection of Fig. 1 suggests that the response of the NBD is as expected, i.e., a general decelerative response with some accelerative peaks. The BD manifest a general accelerative tendency with a late decelerative component. This phenomenon bears further investigation.

\section{REFERENCES}

Briullova, S. V. On some aspects of the orienting reflex in persons having suffered a covert trauma of the brain and in 
neurotic persons. In L. G. Voronin et al (Eds.), Orienting reflex and exploratory behavior. Washington: American Institute of Biological Sciences, 1965. Pp. 343-350.

Gamburg, A. L. Orienting and defensive reactions in post-traumatic cerebroasthenia and encephalopathy. In L. G. Voronin et al (Eds.), Orienting reflex and exploratory behavior. Washington: American Institute of Biological Sciences, 1965. Pp. 360-367.

Graham, F. K., \& Clifton, R. K. Heart-rate change as a component of the orienting response. Psychological Bulletin, $1966,65,305-320$.

Holloway, F. A., \& Parsons, O. A. Habituation of orienting reflex in brain-damaged patients. Psychophysiology, 1971, 8, 623-634.

Keefe, F. B. Cardiovascular response to auditory stimuli. Psychonomic Science, 1970, 19, 335-336.

Lacey, J. L. Somatic response patterning and stress: Some revisions of activation theory. In M. H. Appley and R. Trumbull (Eds.), Psychological stress: Issues in research. New York: Appleton-Century-Crofts, 1967. Pp. 25-37.
Obrist, P., Wood, D. M., \& Perez-Keyes, M. Heart rate during conditioning in humans: Effects of VCS intensity, vagal blockade, and adrenergic block of vasomotor activity. Journal of Experimental Psychology, 1965, 70, 32-42.

Sokolov, E. N. Higher nervous functions: The orienting reflex. Annual Review of Physiology, 1963, 25, 345-580.

Stepanov, A. I. On the problem of using some properties of the orienting reflex for the study of higher nervous activity in man. In L. G. Voronin et al (Eds.), Orienting reflex and exploratory behavior. Washington: American Institute of Biological Sciences, 1965. Pp. 394-398.

Stern, J. A., \& Janes, C. L. Personality and psychopathology. In D. Raskin and W. Prokasy (Eds.), Electrodermal activity in psychological research. New York: Academic Press, in press. Thompson, R. F., \& Spencer, W. A. Habituation: A model phenomenon for the study of neuronal substrates of behavior. Psychological Review, 1966, 73, 16-43.

(Received for publication July 17,1972 ; revision received September 20, 1972.) 